\title{
Untreated Case of Sinonasal Polyposis and its Impact on Nasal Function and Cosmesis
}

\author{
Mirjana Stracenski Perge* \\ General Hospital of Sremska Mitrovica, Urosa Stojsica 4622000 Sremska Mitrovica, Serbia
}

Submission: April 16, 2019; Published: April 25, 2019

*Corresponding author: Mirjana Stracenski Perge, General Hospital of Sremska Mitrovica, Urosa Stojsica 4622000 Sremska Mitrovica, Serbia

\begin{abstract}
The male patient, 51 years old, suffering from difficulties with breathing for 7 years and last 2 years he couldn't breathe at all through his nose. Clinical findings were polyp masses which sweep out forward through nasal corridors. When we performed the CT of paranasal sinuses, we could see that all the sinuses, nasal cavity and nasopharynx were full of polyp masses. Polyposis made a destruction of nasal cartilages, expanded and made a destruction of lateral contours of the nasal pyramid- extended nasal dorsum. However, polyposis made a completely destruction of medial walls of the maxillary sinuses at the height of the medial nasal turbinates. It was indicated and performed an endoscopic endonasal operation and extraction of the polyp masses from the nasal cavity, nasopharynx and sinuses. After an operation patient was satisfied with his breathing and smelling. But our opinion was that nasal function and cosmetic effect after an operation are not perfect due to long lasting of the disease and its destructive effect on the regional anatomical structures.
\end{abstract}

\section{Introduction}

Sinonasal polyposis is a chronic inflammation of the nasal mucosa and mucosa of the paranasal sinuses. The result is polyp formation in the nasal cavity. Nasal polyps are common, affecting up to four percent of the population. They are known to have associations with allergy, asthma, infection, cystic fibrosis, and aspirin sensitivity. However, epidemiological studies provide little evidence to support this relationship with nasal polyposis found in only $1 \%-2 \%$ of patients with positive skin prick tests. In the general population, the prevalence of nasal polyposis is considered to be around $4 \%$. They predominantly affect adults and usually present in patients older than 20 . The symptoms are nasal obstruction, anosmia, rhinorrhoea, post nasal drip, and less commonly facial pain.

\section{Case Report}



Figure 1: Nose Breathing Difficulties.
A male patient, 51 years, couldn't breathe through his nose at all for 2 years. He was mechanic, but he was working in the process of tobacco production. Also, he was a smoker for 30 years, 30 cigarettes per day. At the examination upon presentation it was obvious that he has got a tumor mass in his nasal cavity. From additional disease he had an astrocitoma of the brain and high blood pressure. Until now, he didn't use any kind of therapy for his nose breathing difficulties (Figure 1). CT of the paranasal sinuses was performed and showed that all the sinuses where full of tumor masses. On the first photo you can see our patient polyp masses which sweep out of the nasal corridors. Polyposis made a destruction of nasal cartilages, expanded nasal cavity and made a destruction of lateral contours of the nasal pyramid due to long lasting of the disease. On the second photo we can see a CT scan of paranasal sinuses- coronal image. All the sinuses, nasal cavity was full of polyp masses. On the third photo we can see partial destruction of the nasal cartilages. On the fourth photo we can see completely destruction of the medial walls of the maxillar sinuses at the height of the medial nasal turbinates. The medial walls of the maxillar sinuses were convex to the sinus cavity. Based on anamnestic data, duration of the disease, clinical examination and CT scan I suspected that my patient have been suffering from sinonasal polyposis (Figure 2). I ordinated to him before an operation Pronizon tbl. a $60 \mathrm{mg}$. per so within 3 days, and after that I gradually reduced Pronison tbl. within 7 days. It was indicated an endoscopic endonasal operation and extraction of the polyp masses from the nasal cavity and sinuses. After an operation we administrated hypertonic saline nasal drops - twice daily and Mometason furoat nasal spray- $1 \times 2$ nasal 
spray in the morning. Patohistological founding was- sinonasal polyposis. Patient was satisfied with the result of operation because he could breathe through his nose and he could smell again after many years [1].

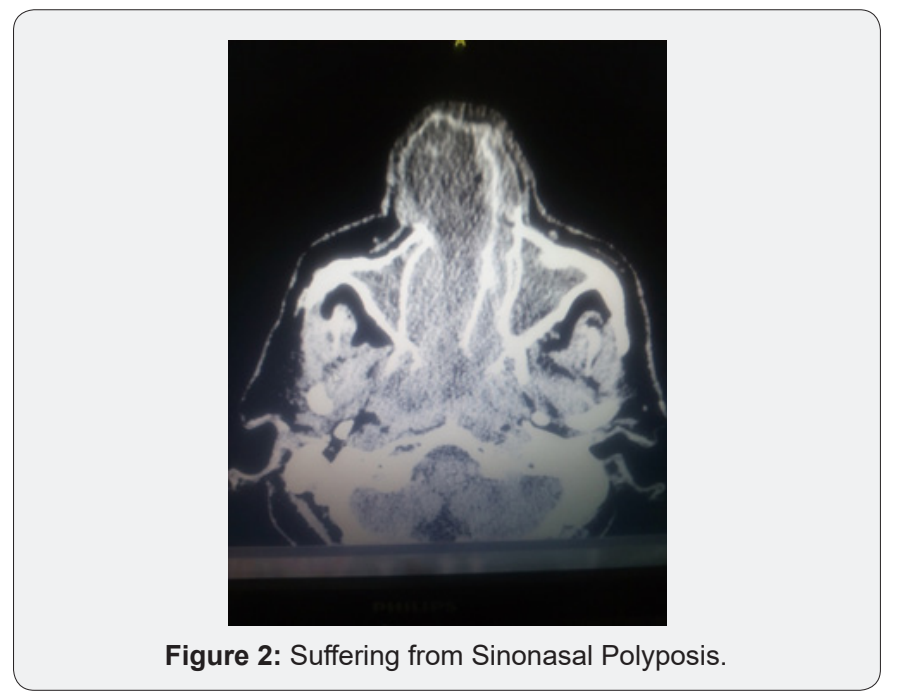

\section{Discussion}

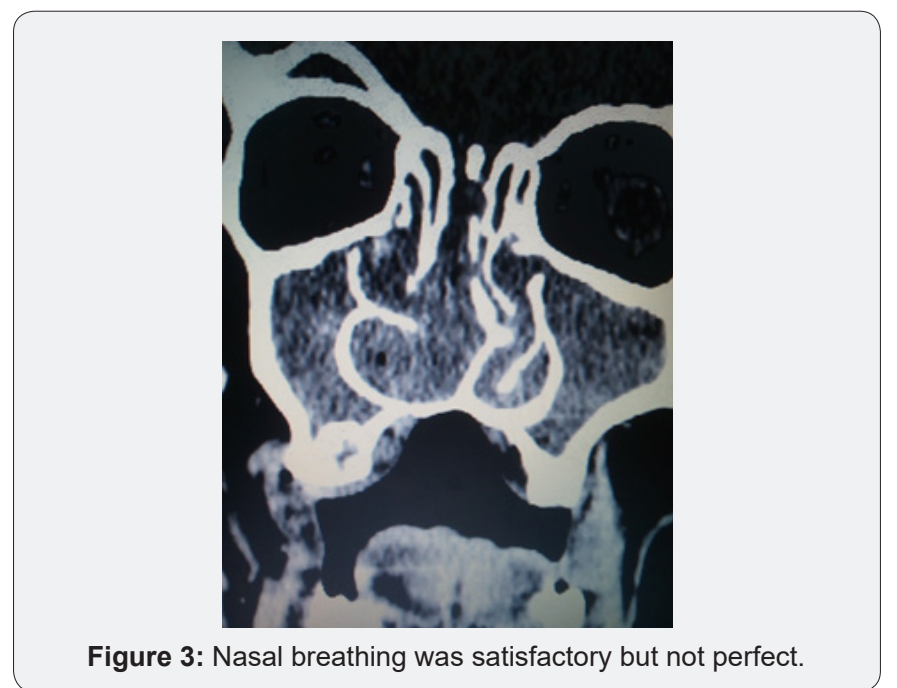

Long lasting of the disease-sinonasal polyposis can have functional and cosmetic consequences. Despite the operation and removing polyp masses from the nose and sinuses, we have got satisfactory functional result [2]. Even though no polyp masses in the nasal cavity were presented, nasal breathing was satisfactory but not perfect (Figure 3). The reason is that the long lasting of the disease had aggressive influence on the nasal mucosa and destroying effect on the nasal turbinates- poliposis expanded nasal cavity as a whole as all the nasal corridors were with meanningly compression atrophy of the bone walls of all the three turbinates. Due to destruction of the medial walls of the maxillar sinuses, anatomical structures were no more physiological- without normal ostiomeatal complex on the lateral wall of the nasal cavity and normal mucociliary clearance. The cosmetic result is less important but not negligible - lateral nasal cartilage were extended - frogy nose and nasal septal cartilage was destroyed partially (Figure 4).

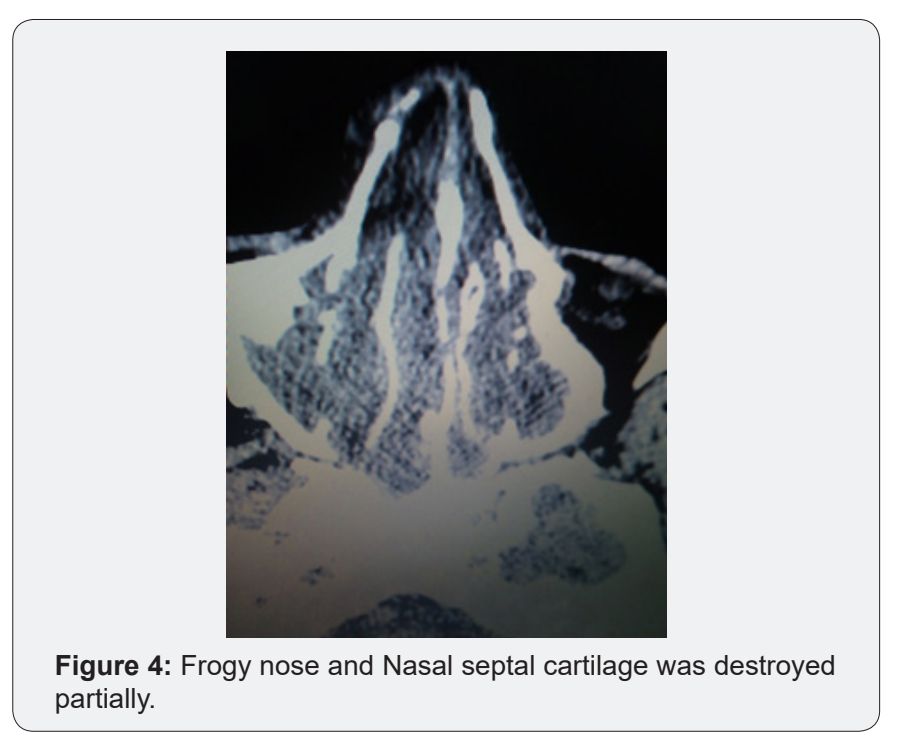

\section{Conclusion}

Sinonasal polyposis is a disease with the well-known symptoms. Patients with suspicion on the sinonasal polyposis should be delivered to the ENT specialist. Also, patient should be treath from the beginning with adequate therapy- saline nasal drops, corticosteroid nasal spray and oral use of corticosteroids if necessary. Despite patohistological finding with benign characteristic, it was obvious that sinonasal polyposis had destructive effect on the regional anatomical structures acting locally by pressure. Due to those consequences it is necessary for every patient to be treat properly in order to prevent this kind of clinical manifestation of the disease.

\section{References}

1. Zoran R (2013) Dudvarski, Prognostički faktori u endoskopskom lečenju nosnosinusne polipoze, University of Belgrade, Faculty of Medicine, Doctoral Dissertation, Beograd, Serbia.

2. Newton RJ, Wong K (2008) A review of nasal polyposis. Ther Clin Risk Manag 4(2): 507-512. 
(C) This work is licensed under Creative CC) Commons Attribution 4.0 License BY DOI: 10.19080/GJO.2019.20.556028
Your next submission with Juniper Publishers will reach you the below assets

- Quality Editorial service

- Swift Peer Review

- Reprints availability

- E-prints Service

- Manuscript Podcast for convenient understanding

- Global attainment for your research

- Manuscript accessibility in different formats ( Pdf, E-pub, Full Text, Audio)

- Unceasing customer service

Track the below URL for one-step submission https://juniperpublishers.com/online-submission.php 